\title{
Mönckeberg's Sclerosis After Sympathetic Denervation in Diabetic and Non-diabetic Subjects
}

\author{
F.-D. Goebel and H.S. Füess1 \\ Medizinische Poliklinik, University of Munich, FRG
}

\begin{abstract}
Summary. Medial arterial calcification is frequently seen in diabetic patients with severe diabetic neuropathy. Sixty patients (19 diabetic and 41 non-diabetic) were examined radiologically for typical Mönckeberg's sclerosis of feet arteries 6-8 years after uni- or bilateral lumbar sympathectomy. Fiftyfive out of 60 patients $(92 \%)$ revealed medial calcification. This calcification was observed in both feet of $93 \%$ of patients, who had undergone bilateral operation. After unilateral sympathectomy the incidence of calcified arteries on the side of operation was significantly higher than that on the contralateral side ( $88 \%$ versus $18 \%, p<0.01)$. Although diabetic patients showed longer stretches of calcificiation than non-dia-
\end{abstract}

betic subjects, the difference was not significant in terms of incidence and length. Of 20 patients who had no evidence of calcinosis pre-operatively, 11 developed medial calcification after unilateral operation exclusively on the side of sympathectomy. In seven patients calcinosis was detected in both feet after bilateral operation. In conclusion, sympathetic denervation is one of the causes of Mönckeberg's sclerosis regardless of diabetes mellitus.

Key words: Mönckeberg's sclerosis, sympathectomy, diabetes mellitus.
In 1903 Mönckeberg [1] described a peculiar calcification of the arterial tunica media stating that this condition was not related to the usual arteriosclerosis. The alteration does not involve the intimal layer of the artery and, therefore vessel obstruction is not a consequence. The aetiology and pathogenesis of this type of calcification still remain unknown. Medial calcification is frequently observed in diabetic patients [2] and the incidence increases with age and duration of diabetes mellitus. After 35 years of diabetes, $94 \%$ present with arterial calcification [3]. A similar incidence of $90 \%$ was found in diabetic subjects with severe diabetic neuropathy (Charcot joints) despite a shorter duration of the metabolic disease [4]. According to Edmonds et al. [5], medial calcification was much more frequent in diabetic subjects with neuropathy, especially of the autonomic nervous system, than in diabetic patients without neuropathy.

In order to test whether medial arterial calcification of arteries might be related to destruction of sympathetic innervation rather than being a consequence of the metabolic disorder alone, we examined 19 diabetic and 41 non-diabetic patients who had been subjected to unior bilateral lumbar sympathectomy several years ago.

\section{Subjects and Materials}

\section{Subjects}

The study included 60 patients (19 diabetic and 41 non-diabetic) who had undergone lumbar sympathectomy between 1974 and 1976 because of ischaemic limb disease. Unilateral sympathectomy had been performed in 33 (10 diabetic and 23 non-diabetic) patients and 27 ( 9 diabetic and 18 non-diabetic) had bilateral operations. At the time of investigation the mean age was 67 years (range 49-82 years). Twenty-seven subjects with angiographically proven macroangiopathy matched for age, sex and diabetes served as controls for the bilaterally sympathectomized patients. In the 17 patients with previously diagnosed diabetes, the diagnosis had been made 10 years ago (mean range: $2-19$ years). In addition, our investigation showed two additional patients of the supposedly non-diabetic group to suffer from this disease.

Despite thorough clinical examination, no signs of diabetic microangiopathy were observed. Vibration sense and deep tendon reflexes were intact in 52 out of 60 patients. Ankle jerks were absent in eight subjects. Three subjects had lost vibration sense. Nerve conduction velocity studies were not performed. All patients had peripheral vascular disease, which had led to sympathectomy, yet only $52 \%$ of them have symptoms of intermittent claudication at the present time.

There were 17 non-insulin-dependent diabetic patients and two additional patients requiring insulin treatment. At the time of the study, their diabetes was well controlled, with glycosylated haemoglobin values below $11 \%$ in 16 patients (microcolumn-chromatography, normal range $4.8-8.5 \%$ ). 


\section{Materials}

Quantitative X-ray studies were performed on $18 \times 24 \mathrm{~cm}$ films which were taken on anterior-posterior view of both feet without magnification. The exposures were made according to a prefixed system with the same X-ray apparatus. Focus was $1.2 \mathrm{~mm}$, focus-film distance $100 \mathrm{~cm}$. The central beam was at a right angle to the object.

Medial calcification appears as a more or less continuous line along one or both sides of the arteries. The X-ray film was considered as positive for medial calcification if at least one typical ring or a linear calcification of $2 \mathrm{~mm}$ was visible between the heads of the metatarsal bones. For quantification the length of continuous calcification was measured on the X-ray films between the first and second metatarsal bone and expressed in $\mathrm{mm}$. In 22 patients (six diabetic and 16 non-diabetic) pre-operative radiographs of the feet were available for comparison. These pictures had been taken because the patients had presented with skin ulceration. Two patients were excluded from the study because medial calcification was already visible on these pre-operative radiographs.

Table 1. Medial calcification in patients after lumbar sympathectomy and in control subjects

\begin{tabular}{lllc}
\hline & \multicolumn{2}{l}{ After lumbar sympathectomy } & $\begin{array}{c}\text { Control } \\
\text { Subjects }\end{array}$ \\
\cline { 2 - 3 } & $\begin{array}{l}\text { Bilateral } \\
\text { operation }\end{array}$ & $\begin{array}{l}\text { Unilateral } \\
\text { operation }\end{array}$ & \\
\hline $\begin{array}{l}\text { Total number } \\
\begin{array}{l}\text { Medial calcification } \\
\text { on both sides }\end{array}\end{array}$ & 27 & 33 & 27 \\
$\begin{array}{l}\text { Medial calcification } \\
\text { on one side }\end{array}$ & 1 & 6 & 3 \\
$\begin{array}{l}\text { Medial calcification } \\
\text { negative }\end{array}$ & 1 & $23^{2}$ & 1 \\
\hline
\end{tabular}

a operated side only
The X-ray films were examined and evaluated by one of the authors without previous knowledge of the medical history and clinical data of the patients (particularly side of operation).

The sign test [6] was used to assess the statistical significance of difference in calcification between both feet after unilateral sympathectomy. Differences of calcification between diabetic and non-diabetic subjects were analyzed by the Mann-Whitney rank test [7].

\section{Results}

The classical linear calcification of feet arteries was found in 55 out of 60 patients (92\%) with lumbar sympathectomy (Table 1).

\section{Results Following Bilateral Sympathectomy}

After bilateral operation 25 of 27 patients $(93 \%)$ revealed Mönckeberg's sclerosis in both feet, one patient on one side only; the remainder had no visible alteration of the vessels at all. In the control group of 27 patients matched to the bilaterally operated subjects, only four $(15 \%)$ revealed medial calcification on X-ray films of their feet.

\section{Results Following Unilateral Sympathectomy}

After unilateral nerve dissection, sclerosis was found on the operated side (Fig. 1) in 29 out of 33 patients (88\%), 23 out of these 29 patients $(80 \%)$ did not show detectable medial calcification on the opposite side. Six patients presented with calcific deposits on the unoperated side also. The four patients, who remained free of medi-

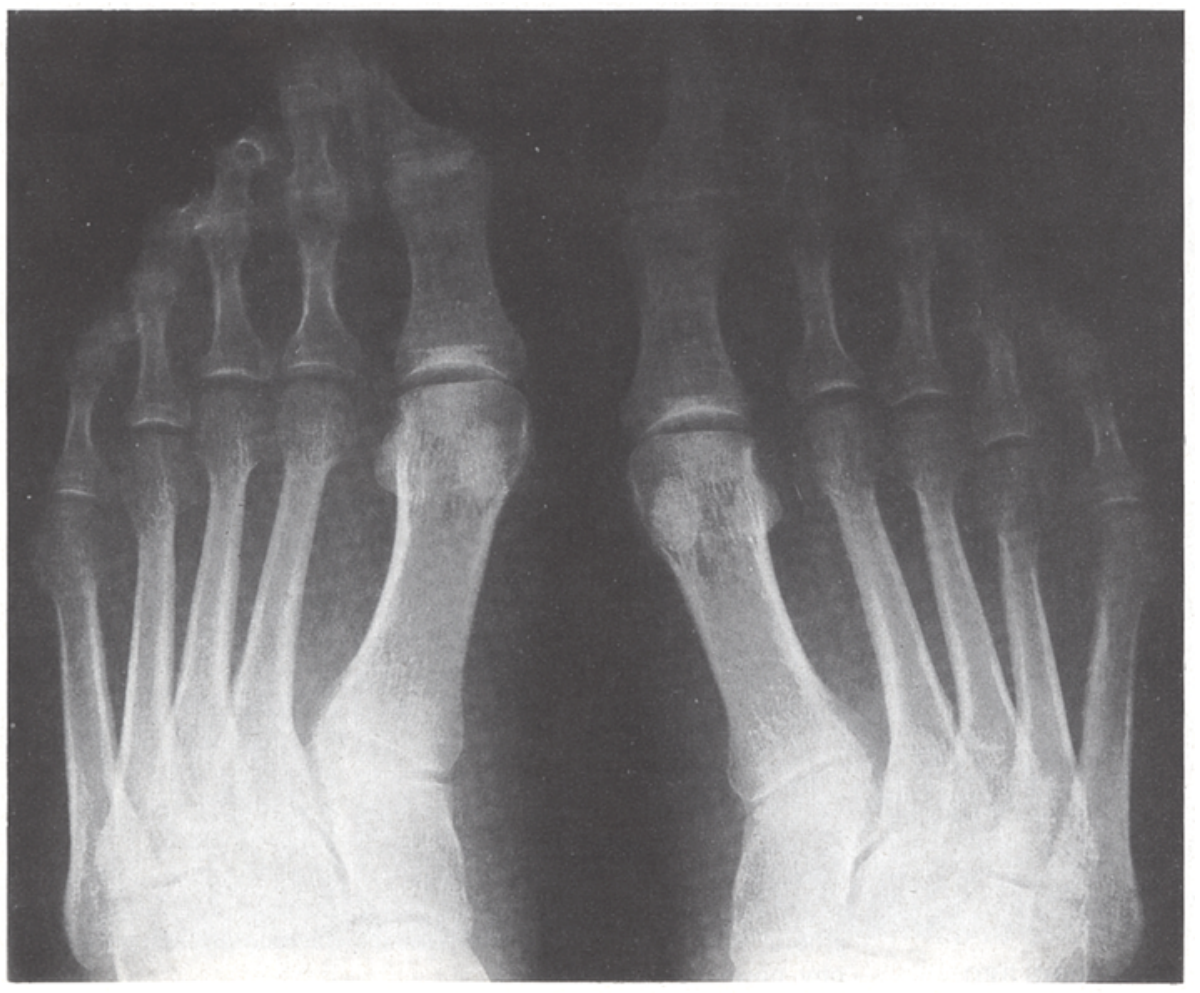

Fig. 1. X-ray film of both feet of a non-diabetic patient 8 years after sympathectomy on the left side 
al calcification on the side of sympathectomy exhibited no sclerotic changes on the other side.

After unilateral sympathectomy quantification of arterial calcification revealed highly significant differences between both feet in the cases of bilateral calcification: the median length of Mönckeberg's sclerosis on the operated side was $33 \pm 7 \mathrm{~mm}$ (mean $\pm S E M$, range $4-68 \mathrm{~mm}$ ), on the other side it amounted to $13 \pm 3 \mathrm{~mm}$ (range $2-41 \mathrm{~mm} ; p<0.01$ ). In every case with bilateral sclerosis the stretch of arterial calcification visible between the first and second metatarsal bone was longer on the side of operation than on the opposite side.

There was almost no difference in the incidence of medial calcification on the side of operation after unilateral sympathectomy in diabetic patients (nine out of ten), and non-diabetic subjects (20 out of $23 ; 90 \%$ versus $87 \%$ ). Yet, $30 \%$ of the diabetic patients (three out of ten) developed sclerosis on both sides, whereas only $13 \%$ (three out of 23 ) of the non-diabetic subjects presented with sclerotic changes in the other foot. The mean length of calcification was longer in the diabetic patients $(19 \pm 7 \mathrm{~mm})$ than in the non-diabetic subjects $(13 \pm 3 \mathrm{~mm})$, although the difference was not statistically significant.

\section{Results in Patients with Pre-operative Radiographs}

Radiographs of 22 patients (six diabetic and 16 nondiabetic subjects) taken before sympathectomy were available for retrospective analysis. On these pre-operative films, only one person with diabetes of 14 years duration at the time of operation revealed medial calcification in both feet. One non-diabetic subject had shown short streaks of calcific deposits on one side. He underwent surgery on the other side and presented with marked Mönckeberg's sclerosis in the arteries of both feet 7 years later. These patients were excluded from the study. Of the remaining 20 patients (one-third of all subjects) with negative $\mathrm{X}$-ray films, 13 underwent unilateral surgery. Typical calcification developed in 11 patients on the operated side without any changes on the contralateral side. One patient was operated on only one side but was later found to have calcinosis in both feet. One patient showed no arterial changes at all 6 years after unilateral nerve dissection. Bilateral sympathectomy was performed in seven patients, all of whom revealed calcification on both sides later.

\section{Discussion}

Mönckeberg's medial sclerosis is usually an incidental radiological finding. Its course is benign and its clinical significance has been questioned, although involvement of visceral arteries such as renal [8] and coronary vessels [9] has been described.

We have observed medial calcification with its typical ring-like and finely granular appearance along the digital arteries of the feet in 55 out of 60 patients after lumbar sympathectomy. After bilateral operation $93 \%$ of these subjects revealed medial calcification compared with only $15 \%$ of 27 matched control subjects. After unilateral sympathectomy a highly significant difference in incidence of vessel calcification was found between the operated and the unoperated legs. These patients served as their own controls. No relevant difference was observed between diabetic and non-diabetic subjects.

The post-operative development of medial calcification was proven in almost one-third of all patients by comparison of pre- and post-operative radiographs. Calcification was not related to age and duration or severity of diabetes. Since all operations were performed in a limited period from 1974 to 1976 and the number of negative $\mathrm{X}$-ray films after operation was very small, time dependency could not be tested.

The incidence of medial calcification without sympathectomy increases with age in diabetic patients as well as in non-diabetic subjects, as does general arteriosclerosis with intimal calcific deposits [10]. Although we cannot exclude the possibility of intimal calcification in some of our patients all of whom had obliterating arteriosclerosis, the characteristic radiological appearance of linear calcification strongly suggests medial sclerosis. No evidence of other diseases known to be associated with medial calcification, such as chronic renal failure [11] or metabolic bone disease [12], was observed in our patients.

Diabetic microangiopathy has also been suggested to cause medial calcification [13], but our diabetic patients did not reveal diabetic retinopathy or nephropathy. In their series of diabetic patients Edmonds et al. [5] found a stronger association of arterial calcification with neuropathy than with retinopathy and nephropathy.

On microscopic examination calcific deposits in Mönckeberg's sclerosis are located exclusively within the medial layer of the arterial wall sparing both the internal and external membranes [14]. Calcification could be the consequence of trophic disturbances of smooth muscle cells in the tunica media after sympathectomy. Morphological changes, such as fragmentation and atrophy of smooth muscle cells, occur after long-term damage of autonomic innervation in animal experiments $[15,16]$. Focal necrosis and degeneration of muscle cells lead to thinning of the medial layer of the arteries followed by calcium salt deposition with structural and functional alterations of the vessels $[17,18]$.

Our findings suggest that medial arterial calcification of the Mönckeberg type in diabetes is probably related to damage or destruction of sympathetic innervation as a part of diabetic neuropathy, rather than to the metabolic disorder alone. Since all our patients have peripheral vascular disease, the possibility of vessel calcification as a consequence of sympathectomy only in, or in conjunction with arteriosclerosis cannot be excluded. 
A diminished vascular flow in ischaemic limb disease might have contributed to the development of medial calcification after sympathectomy.

Nevertheless, the observation of degenerative vascular changes as the consequence of destruction of autonomic innervation deserves further investigation.

Acknowledgments. We are indebted to the Chirurgische Klinik, Nußbaumstraße and Zentrale Röntgenabteilung der Poliklinik, University of Munich, and Dr. S. Schewe for statistical advice. This investigation has been supported in part by a grant of Deutsche Forschungsgemeinschaft (Go 299/2).

\section{References}

1. Mönckeberg JG (1903) Über die reine Mediaverkalkung der Extremitätenarterien und ihr Verhalten zur Arteriosklerose. Virch Arch (Pathol Anat) 171: 141-167

2. Bowen BD, Koenig EC, Viele A (1924) A study of the lower extremities in diabetes as compared with non-diabetic states, from the standpoint of X-ray findings, with particular reference to the relationship of arteriosclerosis and diabetes. Bulletin of the Buffalo General Hospital 2: 35-41

3. White $P(1956)$ Natural course and prognosis of juvenile diabetics. Diabetes 5: 445-450

4. Sinha S, Munichoodappa CS, Kozak GP (1972) Neuro-arthropathy (Charcot joints) in diabetes mellitus. Medicine (Baltimore) 51: $191-210$

5. Edmonds ME, Morrison N, Laws JW, Watkins PJ (1982) Medial arterial calcification and diabetic neuropathy. $\mathrm{Br}$ Med J 284: $928-930$

6. Dixon WJ, Mood AM (1946) The statistical sign test. J Am Stat Assoc 41: 557-566

7. Mann HB, Whitney DR (1947) On a test of whether one of two random variables is stochastically larger than the other. Ann Math Stat 18:50-60
8. Reinhardt K (1973) Nierenarterienverkalkung bei einer Diabetikerin mit Mönckeberg-Sklerose. Fortschr Geb Röntgenstr 119: 363-366

9. Lachman AS, Spray TL, Kerwin DM, Shugoll DI, Roberts WC (1977) Medial calcinosis of Mönckeberg. Am J Med 63: 615-622

10. Neubauer B (1971) A quantitative study of peripheral arterial calcification and glucose tolerance in elderly diabetics and non-diabetics. Diabetologia 7: 409-413

11. Parfitt AM (1969) Soft-tissue calcification in uremia. Arch Intern Med 124: 544-555

12. Amos RS, Wright V (1980) Mönckeberg's arteriosclerosis and metabolic bone disease. Lancet 2: 248-249

13. Christensen NJ (1972) Diabetic macroangiopathy: blood flow and radiologic studies. Adv Metab Disord (Suppl 2): 129-134

14. Ferrier TM (1967) Comparative study of arterial disease in amputated lower limbs from diabetics and non-diabetics (with special reference to feet arteries). Med J Austr 1: 5-11

15. Kerper AH, Collier WD (1926) Pathological changes in arteries following partial denervation. Proc Soc Exp Biol Med 24: 493-494

16. Armaly MF (1968) Degeneration of ciliary muscle and iris sphincter following resection of the ciliary ganglion. Trans Am Ophth Soc $66: 475-502$

17. Bevan RD (1975) Effect of sympathetic denervation on smooth muscle cell proliferation in the growing rabbit ear artery. Circulation Res 37: 14-19

18. Bevan RD, Tsuru H (1979) Long-term denervation of vascular smooth muscle causes not only functional but structural change. Blood Vessels 16: 109-112

Received: 8 September 1982

and in revised form: 14 December 1982

Professor Dr. F.-D. Goebel

Medizinische Poliklinik

Universität München

Pettenkoferstraße 8 a

8000 München 2, FRG 